\title{
A Comunicação no quadro das ciências: uma entrevista com Robert K. Logan
}

\section{Adriana Braga}

\section{Resumo}

Nesta entrevista exclusiva para E-Compós, o Dr.

Logan conta sobre sua carreira, sua colaboração com Marshall McLuhan, Teoria da Comunicação e abordagens interdisciplinares para as Ciências da Comunicação.
Adriana Braga I adrianabraga1@yahoo.com.br

Professora do Programa de Pós-Graduação em Comunicação Social da Pontifícia Universidade Católica do Rio de Janeiro (PUC-Rio). Pesquisadora do Conselho Nacional de Desenvolvimento Científico e Tecnológico (CNPq).
Robert K. Logan é Professor Emérito em Física na Universidade de Toronto e Cientista-chefe do Laboratório de Inovação estratégica do Ontario College of Art and Design.

Ele tem vasta experiência acadêmica na pesquisa em teoria da complexidade, teoria da informação, biologia, ciência ambiental, linguística, design industrial e estudos de mídia. Além disso, é Pesquisador Sênior no Origins Intitute da Universidade McMaster e no Instituto de Biocomplexidade e Informática da Universidade de Calgary.

0 professor Logan trabalhou e publicou com

Marshall McLuhan, e foi muito ativo no mundo dos negócios como o fundador de empresas envolvidas na formação em informática, desenvolvimento Web e gestão do conhecimento. Foi ativista político desde 1974. Entre suas muitas atividades nesta área, serviu como um conselheiro para o Primeiro Ministro Pierre Eliot Trudeau, presidente da ala política de Ontário do Partido Liberal e assessor de vários ministros do gabinete federal. Ele também é autor ou editor de 11 livros, capítulos e 
muitos artigos em revistas científicas. Desde 2010, ele é membro do Conselho Editorial da E-Compós.

Nesta entrevista exclusiva para a E-Compós, Dr. Logan fala sobre sua carreira, sua colaboração com Marshall McLuhan, Teoria da Comunicação e abordagens interdisciplinares em Ciências da Comunicação.

\section{Adriana Braga: Professor Logan, você é um} cientista de renome na área de Física, e, ao mesmo tempo, tem um trabalho expressivo na Teoria da Comunicação. Você pode nos contar sobre sua carreira e como chegou a relacionar essas áreas aparentemente tão distantes?

Robert K. Logan: Eu ministrei um curso para estudantes de humanidades chamado "A Poesia da Física" - eu explicava as ideias da Física sem matemática. Isso levou McLuhan a me convidar para almoçar com ele e a partir disso elaboramos nosso primeiro artigo juntos. Eis como isso aconteceu. Eu estava organizando um seminário, "O Clube de Gnu” em estudos do futuro no New College, University of Toronto em 1974, e recrutei o Prof. Arthur Porter, engenheiro industrial. Ele convidou Marshall para se juntar a nós e mencionou o meu nome. McLuhan tinha ouvido falar sobre o meu curso "A Poesia da Física e a Física da Poesia" e disse a Porter para me convidar para ir à coach house ${ }^{1}$ para almoçar com ele. Eu fiquei muito animado para almoçar com um sujeito tão famoso. Almoçamos na cantina da faculdade em St. Mike e, logo que nos sentamos com nossas bandejas, McLuhan imediatamente me perguntou o que eu tinha aprendido ensinando a Poesia da Física. Eu expliquei que era fascinado pelo problema colocado por Joseph Needham, em seu livro The Grand Titration, sobre o porquê da ciência abstrata ter começado no Ocidente, apesar do fato de tantas tecnologias terem se originado na China. Propus que, uma vez que o monoteísmo e a lei codificada eram peculiaridades do Ocidente, juntos, dariam lugar a uma noção de lei universal, e que isso poderia explicar o paradoxo de Needham. Marshall McLuhan acenou com a cabeça em concordância e depois perguntou-me incisivamente o que mais temos no Ocidente de que não está presente na China? Eu estava totalmente intimidado por esse sujeito que parecia estar falando para mim, a 100 milhas por hora. Eu não consegui pensar e, finalmente, disse: "eu desisto." Ele sorriu e disse: "o alfabeto, é claro!"

Deixei escapar um gemido, porque eu imediatamente vi por onde ele estava indo. Lembrei que ele havia mostrado a conexão do alfabeto com a ciência abstrata e a lógica dedutiva em The Gutenberg Galaxy e Understanding Media. Tudo se tornou tão óbvio - o alfabeto serve como um modelo para a classificação, análise, codificação e decodificação. Para usar o alfabeto para escrever é preciso analisar cada palavra em seus fonemas básicos e eles representam cada fonema com um sinal de sentido visual, uma letra. Assim, a escrita com alfabeto é a codificação de sons em sinais visuais, e a leitura de um texto alfabético é a decodificação dos sinais visuais de volta em sons. Na medida em 
que a classificação ocorre, o alfabeto permite que cada palavra e cada nome possam ser ordenados alfabeticamente, como é o caso em um dicionário.

Tomado como um todo, o alfabeto promove a classificação, a codificação e a análise, competências básicas necessárias para a ciência abstrata e a lógica dedutiva. Percebendo que nossas explicações independentes para o surgimento da ciência abstrata no Ocidente eram complementadas e reforçadas mutuamente, nós combinamos nossas ideias e desenvolvemos a hipótese de que o alfabeto fonético, a lei codificada, o monoteísmo, a ciência abstrata e a lógica dedutiva foram ideias originais do Ocidente.

Todas estas inovações, incluindo o alfabeto, surgiram dentro de uma zona geográfica muito estreita entre o sistema Tigre-Eufrates e o Mar Egeu, e dentro de um prazo muito estreito, entre 2000 aC e 500 aC. Não acreditamos que isso seja um acidente. Embora não sugerindo uma ligação de causalidade direta entre o alfabeto $e$ as outras inovações, afirmamos, no entanto, que o alfabeto fonético (ou silábico-fonético) desempenhou um papel particularmente dinâmico dentro dessa constelação de eventos e forneceu uma base ou quadro para o desenvolvimento mútuo destas inovações. 0 efeito do alfabeto e o pensamento abstrato, lógico e sistemático que ele encorajou explicam por que a ciência começou no Ocidente e não no Oriente, apesar da enorme sofisticação tecnológica dos chineses, os inventores do papel, da metalurgia, de sistemas de irrigação, de arreios de animais, tintas de impressão, tipos móveis, pólvora, foguetes, porcelana e seda. Também deve ser dado crédito ao monoteísmo e à lei codificada pelo papel que desempenharam no desenvolvimento da noção de universalidade, um componente essencial da ciência. Quase todos os primeiros cientistas, Tales de Mileto, Anaximandro, Anaxágoras e Heráclito, foram também legisladores em suas comunidades e inclinados ao monoteísmo. Todos eles acreditavam que um pricípio unificador governava o universo.

Assim, no nosso primeiro encontro na lanchonete da faculdade, decidimos escrever estas ideias e publicá-las como um artigo. Durante esta conversa toda eu estava tomando notas. McLuhan só falava. Em um certo momento em nossa discussão ele me disse: "por favor, escreva essas ideias e podemos discuti-las melhor". Assim que deixei o almoço, fui para casa e escrevi as ideias que tinhamos discutido. Eu lembro de estar muito nervoso porque eu não tinha certeza de como McLuhan entenderia a noção de que o alfabeto fonético ajudou os hebreus a conceber a ideia do monoteísmo e da existência de Deus. Eu estava preocupado, pois isso poderia ofender as sensibilidade catõlica romana de McLuhan. Eu não precisava ter me preocupado. Ele estava confortável com essa ideia e, basicamente, aceitou o paper praticamente como eu o havia redigido. Enquanto eu lia para ele enquanto ele estava deitado em seu sofá, ele me pedia para mudar uma frase ou palavra aqui e ali. Ele ampliou alguns pontos que estavam no texto, mas, basicamente, aceitou o documento como eu tinha lido para ele. Ele também sugeriu o título, Alphabet, Mother of Invention (McLuhan $\&$ Logan, 1977).

Uma vez que ele terminou de fazer suas 
sugestões, ele me pediu para dar o manuscrito com suas alterações à sua secretária Marg Stewart para ser datilografado. Ele enviou o paper para Neil Postman, que era o editor da Etcetera, a revista da International Society for General Semantics. O texto foi aceito e Neil Postman enviou uma nota declarando que foi o melhor paper que McLuhan tinha escrito a partir de um ponto de vista do lado esquerdo do cérebro. Eu havia escrito o nosso paper naquela primeira noite após a nossa discussãoalmoço como se eu estivesse escrevendo uma paper de Física.

\section{Adriana Braga: Na sua opinião, que contribuições a Física e a Comunicação podem oferecer uma à outra?}

Robert K. Logan: Eu usei a teoria da complexidade da Física para explicar a evolução da linguagem falada para a escrita e da matemática para a ciência, para a computação e para a Internet no meu livro The Sixth Language. Explicar o modo como eu articulo a Física à Comunicação necessitará de um pouco de texto.

A Evolução das seis formas de Linguagem O desenvolvimento da linguagem é uma característica do Homo Sapiens que a distingue de todas as outras espécies. Todas as espécies se comunicam, como o comportamento das abelhas, pássaros e primatas demonstra. Nenhuma outra espécie, no entanto, criou uma ferramenta perfeita para o pensamento abstrato como a linguagem. Eu acredito que a linguagem verbal como forma de expressão surgiu da necessidade de hominideos pré-humanos de conceitualizar. o mundo dos hominídeos se tornou progressivamente mais complexo à medida em que eles adquiriram a capacidade de fabricar ferramentas, de controlar o fogo, e a inteligência social necessária para viver em grandes grupos, para compartilhar as vantagens de fogo, para a caça coordenada em larga escala por larga escala coordenada caça, e para a comunicação mimética ou sinalética através de gestos, sinais manuais, linguagem corporal e não-verbal de vocalização.

O caos que surgiu com essa complexidade deu origem a um novo nivel de ordem na forma de linguagem falada, o que representa, nos termos da teoria do caos e da complexidade de Prigogine, uma bifurcação do não-verbal para a linguagem verbal e comunicação. Também representa uma bifurcação do pensamento baseado na percepção para o pensamento baseado em conceitos ou conceitualização. Acredito que todas as habilidades dos hominídeos listadas acima, da ferramenta à comunicação mimética, foram baseadas em percepção, e que o surgimento de conceitos na forma de palavras aumentou as chances de sobrevivência desses hominídeos, que poderiam verbalizar seus pensamentos e, portanto, conceituar. Os primeiros conceitos foram as palavras, que serviram tanto como metáforas quanto como atratores para certos conjuntos de percepções. A palavra água uniu todas as experiências com a água, quer ela estivesse sendo bebida, servindo para banho ou caindo em forma de chuva. Essa transição do pensamento baseado em percepção para o pensamento conceitual e da linguagem não-verbal para a linguagem verbal também representou a transição ou bifurcação de 
hominídeos pré-humanos para seres humanos plenamente desenvolvidos, o Homo sapiens sapiens. 0 cérebro dos hominídeos era basicamente um processador de percepção, mas com a linguagem ele se bifurcou na mente humana que podia conceitualizar e processar informações abstratas. A mente é o cérebro mais a linguagem. Essa linha de pensamento justifica um dos pressupostos básicos deste estudo, a saber, que a linguagem é mais do que apenas um sistema de comunicações - é também uma ferramenta de informática. Articula-se igualmente com a hipótese de Vygotsky de que a evolução do discurso está relacionada com o uso e fabricação de ferramentas e o crescimento da caixa craniana. "A evolução biológica está ligada ao desenvolvimento da cultura, uma vez que o uso da linguagem parece obviamente associado ao uso habitual de ferramentas (limitando o uso de gestos) e com o crescimento da inteligência humana." (Vygotsky 1962).

Os dois principais usos da fala são para abstrair experiência através de conceitualização e comunicação. Nas sociedades pré-letradas, a fala foi o meio para interações sociais e uma ferramenta para a coordenação das atividades que exigem cooperação, tais como a caça ou a coleta de alimentos. A linguagem falada evoluiu funções mais complexas e foi usada no aparato cultural de uma sociedade para contar contos e cantar canções. Eventualmente, a fala foi usada como um meio de registrar (ou arquivar) e recuperar informações culturais na forma de poemas, contos e canções populares. Como as histórias se tornaram mais complexas, o discurso foi usado para organizar a informação armazenada nestes formatos. Formas organizacionais, tais como rima, ritmo, métrica, e enredo, por sua vez, tornaram-se ferramentas de informação que permitiram que uma maior quantidade de dados fossem armazenados e recuperados com êxito (Havelock, 1963).

Eventualmente, porém, a fala e a capacidade humana de memorização encontraram limites para a quantidade de dados que podem ser registrados desta maneira. Sistemas de escrita e notações numéricas permitiram que a quantidade e o tipo de dados armazenados se expandissem enormemente. A invenção da escrita e das notações matemáticas também teve um tremendo impacto sobre a capacidade informática da linguagem e do pensamento humanos. Registros escritos deram origem a novas formas de classificação, análise e outras formas de processamento de informações. $O$ aumento da capacidade de processamento de informações que as notações matemáticas tornaram possivel é facilmente confirmada através da comparação da complexidade de cálculos matemáticos que podem ser feitos com lápis e papel em comparação com cálculos feitos apenas de cabeça.

0 aumento na quantidade e sofisticação dos dados que a escrita e a matemática tornaram possivel eventualmente deu origem a uma nova forma de linguagem e processamento de informações - a linguagem da ciência. A atividade científica, quer seja concreta ou abstrata, limita-se a sociedades letradas. A ciência não é apenas o acúmulo de novos conhecimentos sobre a natureza; ela também consiste em dar uma forma para este conhecimento através da sua organização 
de forma sistemática. É uma forma de gestão do conhecimento. $O$ armazenamento e processamento eficaz de informações que a escrita e a matemática tornaram possível permitiram que estudiosos coletassem e reunissem tantos dados que a única maneira de lidar com a complexidade e a sobrecarga de informações que se seguiu foi desenvolver um novo modo de organização, conhecido como o método científico.

A ciência e o método científico, no entanto, também se tornaram uma ferramenta para gerar ainda mais atividades de coleta de informações. A sobrecarga de informações que a ciência moderna e o método científico ajudaram a gerar se tornou tão grande no século XX que levou ao desenvolvimento de computadores como uma forma de ajudar os cientistas a lidar com a enorme quantidade de dados acumulados e os cálculos complexos que eles precisavam executar.

O trabalho de Vygotsky mostrou como as crianças descobrem que a linguagem, um meio de comunicação, também pode ser usada como uma ferramenta para processar informações e resolver problemas. Pode-se facilmente estender essa noção para trás no tempo e assumir que em algum momento, os seres humanos descobriram que o seu sistema de sinais verbais vocalizado poderia ser usado internamente, como uma ferramenta para pensar. Pode até ser o caso que a fala surgiu para tornar possivel o pensamento conceitual e foi então utilizado para fins de comunicação. E uma terceira possibilidade é que ela surgiu, simultaneamente, tanto como uma ferramenta para pensar e como um meio de comunicação.
A extensão da fala e sua concretização na forma de escrita, matemática, ciência, computação e Internet alavancou a linguagem como uma ferramenta para pensar e ampliou sua capacidade informacional, preservando a sua função de comunicação. A motivação para o surgimento de novas formas de linguagem, no entanto, parece ter sido rigorosamente a necessidade de uma maior capacidade informacional, e não o crescimento comunicacional.

A escrita foi inicialmente usada não para comunicação, mas para a manutenção de registros contábeis. Para o período logo após o surgimento da escrita, "poucos documentos literários [foram] descobertos, embora o mesmo período tenha rendido dezenas de milhares de placas de argila com textos econômicos e administrativos e centenas de inscrições votivas" (Kramer, 1959). As primeiras palavras a serem escritas na língua suméria foram as palavras que designavam produtos agrícolas recolhidos como tributo pelos sacerdotes que dirigiam o sistema de irrigação. Eles usaram a escrita para registrar quem pagava os seus impostos ao Estado. Numerais escritos foram inventados ao mesmo tempo que a escrita, para manter o controle das quantidades de cada mercadoria que foram pagas como tributo. A invenção da escrita e dos números abstratos ilustra o "teorema da variedade de requisitos" do ciberneticista Ross Ashby (Ashby 1957), bem como a noção de que a necessidade é a mãe da invenção. De acordo com Ashby, os gestores só podem controlar um sistema se conseguirem criar um modelo do mesmo que contenha a variedade ou complexidade dos requisitos 
que permitam descrevê-lo. Os sacerdotes que executavam o sistema de irrigação precisaram coletar tributos dos agricultores, a fim de alimentar os trabalhadores de irrigação. Eles, portanto, necessitaram armazenar e manter o controle de um complexo conjunto de dados. Dado que a memória humana tem dificuldade em lidar com mais de sete elementos de uma só vez, a única maneira de os sacerdotes se lembrarem daqueles que tinham pago o seu tributo e dos que não tinham foi criar registros permanentes dos tributos. Foi somente após a invenção da escrita para fins de controle econômico que a ela também foi utilizada para fins de comunicação, e, eventualmente, para outras aplicações, como a composição de histórias ou poemas escritos.

O desenvolvimento da ciência também foi motivado por considerações puramente informacionais. A ciência abstrata permitiu um maior controle da natureza através de uma melhor organização das informações e da capacidade de fazer previsões. 0 método científico capacitou os cientistas com a variedade de requisitos que permitiram controlar um corpo de conhecimento que as linguagens escrita e matemática não tinham sido capazes de gerenciar.

A invenção da computação é ainda outro exemplo do impulso informacional levando ao desenvolvimento da linguagem. Sem computação, cientistas naturais e sociais não teriam sido capazes de gerenciar a sobrecarga de informação criada por suas disciplinas. Fo $i$ somente após a sua primeira utilização como um dispositivo informacional que a computação também foi usada para comunicações e, portanto, o seu nome em inglês é "computer" (que significa "calculador") e não "processador de palavras", mesmo que um número muito maior de usuários use computadores para trabalhar com palavras do que com cálculos. A Internet é outro exemplo de uma nova forma de linguagem que emergiu de uma sobrecarga de informação. A computação aumentou o enorme número de mensagens que precisavam ser comunicadas, bem como o número de pessoas que precisavam ser comunicadas. Como o mundo encolheu para as dimensões de uma aldeia global o número de pessoas na vila com quem se queria comunicar aumentou dramaticamente. Essa sobrecarga de informações ou fila de trânsito de mensagens deu origem a redes, sistemas cliente-servidor e, finalmente, a Internet. A Internet, por oposição aos sistemas cliente-servidor, foi capaz de abraçar toda a comunidade global em um único abraço eletrônico. Como tantas vezes acontece, uma mudança quantitativa criou uma mudança qualitativa, e como resultado uma nova linguagem surgiu, a Internet ou a sexta linguagem.

Começando com a capacidade de gravar ideias através da escrita e da notação matemática, o pensamento humano tornou-se cada vez mais complexo. A necessidade de modelar fenômenos mais complexos impulsionou o desenvolvimento dos seis modos de linguagem. Conseqüentemente, cada novo modo de linguagem é informacionalmente mais poderoso do que seus antecessores, mas ao mesmo tempo, um pouco menos poético com exceção da Net, que por causa de seus elementos visuais e de áudio é capaz de incorporar as artes e o 
modo de expressão artística. $O$ nosso modelo de evolução da linguagem é aquele em que a capacidade de processamento de informação da linguagem torna-se cada vez mais importante à medida em que complexidade do pensamento humano aumenta. É essencial lembrar, no entanto, que todas as formas de linguagem possuem uma dupla capacidade de comunicação e processamento de informações. Os computadores e a Internet são também dispositivos de comunicação e a palavra falada tem uma capacidade informacional. Ambos os recursos da linguagem devem ser abordados quando consideramos a natureza do trabalho $e$ da educação.

Adriana Braga: Durante muito tempo, o potencial acadêmico de entrelaçamento de diferentes campos disciplinares, tem sido às vezes descrito por termos como "interdisciplinaridade" ou "multidisciplinaridade", e tem sido apresentado como um caminho promissor para a Ciência. Por outro lado, na vida institucional acadêmica corrente, há uma forte resistência a práticas acadêmicas desse tipo. Por exemplo, muitos departamentos exigem uma formação "puro sangue" para candidatos a bolsas de investigação e postos de trabalho, e pesquisadores "indisciplinares" podem ter suas carreiras sabotadas por fazê-lo. Como cientista, você tem trabalhado por muitos anos em um Departamento de Física, mas tem interesses de pesquisa na Comunicação. Como você avalia a sua experiência nos níveis científico, político e institucional?

Robert K. Logan: As fronteiras entre as disciplinas foram desenvolvidas por especialistas que, como disse McLuhan saber mais e mais sobre cada vez menos, até que eles saibam tudo sobre nada. É somente através do cruzamento das fronteiras disciplinares que podemos explicar fenômenos complexos.

Adriana Braga: Como você vê os estudos de comunicação contemporânea (um campo acadêmico jovem, nascido na confluência de várias disciplinas) em relação ao universo da Ciência?

Robert K. Logan: Os estudos de comunicação fazem parte da ciência e a ciência é parte da comunicação. Eles dependem uns dos outros.

\section{Adriana Braga: Em seu livro The}

Sixth Language, você relaciona com a aquisição de certas tecnologias como estando profundamente envolvidas com as transformações sociais (por exemplo, agricultura permitindo o surgimento da aristocracia, ou a alfabetização estando envolvida no surgimento da classe média). Como você avalia as transformações na ordem social que podem ser trazidas com a introdução de comunicações pessoais mediadas por dispositivos como tablets ou smartphones? Qual seria a "sétima linguagem"?

Robert K. Logan: Tudo o que McLuhan disse que aconteceria com os meios elétricos aconteceu com a mídia digital, mas de modo ainda mais intenso. A sétima linguagem, se eu tivesse que adivinhar, seria a mídia social ou talvez o Google, porque o Google é um mapa da Web. 


\begin{tabular}{|l|l|l|}
\hline \begin{tabular}{|l|l|} 
Communication on Sciences \\
Framework: an interview with \\
Robert K. Logan
\end{tabular} & $\begin{array}{l}\text { La Comunicación en el Cuadro } \\
\text { de las Ciéncias: una entrevista } \\
\text { Con Robert K. Logan }\end{array}$ \\
\hline $\begin{array}{lll}\text { Abstract: } \\
\text { In this exclusive interview for E-Compós, Dr. } \\
\text { Logan tells about his career, his collaboration } \\
\text { with Marshall McLuhan, Communication } \\
\text { Theory and interdisciplinary approaches to } \\
\text { Communication Sciences. }\end{array}$ & $\begin{array}{l}\text { Resumen: } \\
\text { En esta entrevista exckusiva para E-Compós, Dr. } \\
\end{array}$ & $\begin{array}{l}\text { Logan habla cerca de su carrera, su colaboración } \\
\text { con Marshall McLuhan, Teoria de la Comunicación } \\
\text { y abordajes interdisciplinarias para las Ciéncias de } \\
\text { la Comunicación. }\end{array}$ \\
\hline
\end{tabular}




\section{Expediente}

A revista E-Compós é a publicação científica em formato eletrônico da Associação Nacional dos Programas de Pós-Graduação em Comunicação (Compós). Lançada em 2004, tem como principal finalidade difundir a produção acadêmica de pesquisadores da área de Comunicação, inseridos em instituições do Brasil e do exterior.

\section{E-COMPÓS I www.e-compos.org.br I E-ISSN 1808-2599}

Revista da Associação Nacional dos Programas de Pós-Graduação em Comunicação.

Brasília, v.14, n.1, jan/abr. 2011

A identificação das edições, a partir de 2008

passa a ser volume anual com três números.

\section{CONSELHO EDITORIAL}

Afonso Albuquerque, Universidade Federal Fluminense, Brasil Alberto Carlos Augusto Klein, Universidade Estadual de Londrina, Brasil Alex Fernando Teixeira Primo, Universidade Federal do Rio Grande do Sul, Brasil Ana Carolina Damboriarena Escosteguy, Pontifícia Universidade Católica do Rio Grande do Sul, Brasil

Ana Gruszynski, Universidade Federal do Rio Grande do Sul, Brasil Ana Silvia Lopes Davi Médola, Universidade Estadual Paulista, Brasil André Luiz Martins Lemos, Universidade Federal da Bahia, Brasil Ângela Freire Prysthon, Universidade Federal de Pernambuco, Brasil Angela Cristina Salgueiro Marques, Faculdade Cásper Líbero (São Paulo), Brasil Antônio Fausto Neto, Universidade do Vale do Rio dos Sinos, Brasil Antonio Carlos Hohlfeldt, Pontifícia Universidade Católica do Rio Grande do Sul, Brasil Antonio Roberto Chiachiri Filho, Faculdade Cásper Líbero, Brasil Arlindo Ribeiro Machado, Universidade de São Paulo, Brasil Arthur Autran Franco de Sá Neto, Universidade Federal de São Carlos, Brasil Benjamim Picado, Universidade Federal Fluminense, Brasil César Geraldo Guimarães, Universidade Federal de Minas Gerais, Brasil Cristiane Freitas Gutfreind, Pontifícia Universidade Católica do Rio Grande do Sul, Brasil Denilson Lopes, Universidade Federal do Rio de Janeiro, Brasil Denize Correa Araujo, Universidade Tuiuti do Paraná, Brasil Edilson Cazeloto, Universidade Paulista, Brasil Eduardo Peñuela Cañizal, Universidade Paulista, Brasil Eduardo Vicente, Universidade de São Paulo, Brasi Eneus Trindade, Universidade de São Paulo, Brasil Erick Felinto de Oliveira, Universidade do Estado do Rio de Janeiro, Brasil Florence Dravet, Universidade Católica de Brasília, Brasil Francisco Eduardo Menezes Martins, Universidade Tuiuti do Paraná, Brasil Gelson Santana, Universidade Anhembi/Morumbi, Brasil Gilson Vieira Monteiro, Universidade Federal do Amazonas, Brasi Gislene da Silva, Universidade Federal de Santa Catarina, Brasi Guillermo Orozco Gómez, Universidad de Guadalajara Gustavo Daudt Fischer, Universidade do Vale do Rio dos Sinos, Brasil Hector Ospina, Universidad de Manizales, Colômbia Herom Vargas, Universidade Municipal de São Caetano do Sul, Brasil leda Tucherman, Universidade Federal do Rio de Janeiro, Brasil Inês Vitorino, Universidade Federal do Ceará, Brasil Janice Caiafa, Universidade Federal do Rio de Janeiro, Brasil Jay David Bolter, Georgia Institute of Technology Jeder Silveira Janotti Junior, Universidade Federal de Pernambuco, Brasil João Freire Filho, Universidade Federal do Rio de Janeiro, Brasil
John DH Downing, University of Texas at Austin, Estados Unidos José Afonso da Silva Junior, Universidade Federal de Pernambuco, Brasil José Carlos Rodrigues, Pontifícia Universidade Católica do Rio de Janeiro, Brasil José Luiz Aidar Prado, Pontifícia Universidade Católica de São Paulo, Brasil José Luiz Warren Jardim Gomes Braga, Universidade do Vale do Rio dos Sinos, Brasi Juremir Machado da Silva, Pontifícia Universidade Católica do Rio Grande do Sul, Brasil Laan Mendes Barros, Universidade Metodista de São Paulo, Brasil Lance Strate, Fordham University, USA, Estados Unidos Lorraine Leu, University of Bristol, Grã-Bretanha Lucia Leão, Pontifícia Universidade Católica de São Paulo, Brasil Luciana Panke, Universidade Federal do Paraná, Brasil Luiz Claudio Martino, Universidade de Brasília, Brasil Malena Segura Contrera, Universidade Paulista, Brasil Márcio de Vasconcellos Serelle, Pontifícia Universidade Católica de Minas Gerais, Brasi Maria Aparecida Baccega, Universidade de São Paulo e Escola Superior de Propaganda e Marketing, Brasil

Maria das Graças Pinto Coelho, Universidade Federal do Rio Grande do Norte, Brasil Maria Immacolata Vassallo de Lopes, Universidade de São Paulo, Brasil Maria Luiza Martins de Mendonça, Universidade Federal de Goiás, Brasil Mauro de Souza Ventura, Universidade Estadual Paulista, Brasil Mauro Pereira Porto, Tulane University, Estados Unidos Nilda Aparecida Jacks, Universidade Federal do Rio Grande do Sul, Brasil Paulo Roberto Gibaldi Vaz, Universidade Federal do Rio de Janeiro, Brasil Potiguara Mendes Silveira Jr, Universidade Federal de Juiz de Fora, Brasil Renato Cordeiro Gomes, Pontifícia Universidade Católica do Rio de Janeiro, Brasi Robert K Logan, University of Toronto, Canadá

Ronaldo George Helal, Universidade do Estado do Rio de Janeiro, Brasil Rosana de Lima Soares, Universidade de São Paulo, Brasil Rose Melo Rocha, Escola Superior de Propaganda e Marketing, Brasil Rossana Reguillo, Instituto de Estudos Superiores do Ocidente, Mexico Rousiley Celi Moreira Maia, Universidade Federal de Minas Gerais, Brasil Sebastião Carlos de Morais Squirra, Universidade Metodista de São Paulo, Brasil Sebastião Guilherme Albano da Costa, Universidade Federal do Rio Grande do Norte, Brasil

Simone Maria Andrade Pereira de Sá, Universidade Federal Fluminense, Brasil Tiago Quiroga Fausto Neto, Universidade de Brasília, Brasil Suzete Venturelli, Universidade de Brasília, Brasil

Valério Cruz Brittos, Universidade do Vale do Rio dos Sinos, Brasil Valerio Fuenzalida Fernández, Puc-Chile, Chile Veneza Mayora Ronsini, Universidade Federal de Santa Maria, Brasil Vera Regina Veiga França, Universidade Federal de Minas Gerais, Brasil

\section{COMISSÃO EDITORIAL}

Adriana Braga I Pontifícia Universidade Católica do Rio de Janeiro, Brasil Felipe Costa Trotta I Universidade Federal de Pernambuco, Brasil CONSULTORES AD HOC

Édison Gastaldo I Universidade Federal Rural do Rio de Janeiro, Brasil Gisela Grangeiro da Silva Castro, Escola Superior de Propaganda e Marketing, Brasil Helio Kuramoto, Instituto Brasileiro de Informação em Ciência e Tecnologia, Brasil Juliano Maurício de Carvalho, Universidade Estadual Paulista, Brasil Maria Helena Weber, Universidade Federal do Rio Grande do Sul, Brasi Paulo Carneiro da Cunha Filho, Universidade Federal de Pernambuco, Brasil Vera Regina Veiga França, Universidade Federal de Minas Gerais, Brasil EDIÇÃO DE TEXTO E RESUMOS I Susane Barros SECRETÁRIA EXECUTIVA I Juliana Depiné EDITORAÇ̃̃o ELETRÔNICA I Roka Estúdio
COMPóS I www.compos.org.br

Associação Nacional dos Programas de Pós-Graduação em Comunicação

Presidente

Itania Maria Mota Gomes

Universidade Federal da Bahia, Brasil

itania@ufba.br

Vice-presidente

Julio Pinto

Pontifícia Universidade Católica de Minas Gerais, Brasil juliopinto@pucminas.br

Secretária-Geral

Ana Carolina Escosteguy

Pontifícia Universidade Católica do Rio Grande do Sul, Brasil carolad@pucrs.br 